\title{
Allelic Variation for Prolamins in Spanish Durum Wheat Landraces and Its Relationship with Quality Traits
}

\author{
Efraín A. Chacón, Francisco J. Vázquez, Patricia Giraldo ${ }^{\mathbb{D}}$, José M. Carrillo, Elena Benavente *ii \\ and Marta Rodríguez-Quijano * \\ Department of Biotechnology-Plant Biology, School of Agricultural, Food and Biosystems Engineering, \\ Universidad Politécnica de Madrid, 28040 Madrid, Spain; efrain.chamor@upm.es (E.A.C.); \\ josefrancisco.vazquez@upm.es (F.J.V.); patricia.giraldo@upm.es (P.G.); josem.carrillo@upm.es (J.M.C.) \\ * Correspondence: e.benavente@upm.es (E.B.); marta.rurquiaga@upm.es (M.R.-Q.)
}

Received: 7 December 2019; Accepted: 13 January 2020; Published: 16 January 2020

\begin{abstract}
Wheat landraces are currently being explored mainly as a source of allelic variation related to crop resilience and low-input adaptation. Characterization of their high- and low-molecular weight glutenin subunits can aid breeders to select as donor local materials those ensuring good end-use properties in the derived elite cultivars. By using protein electrophoretic methods, we have determined the prolamin allelic profile of 116 Spanish durum wheat landraces. Their quality properties (as defined by grain protein content, sodium dodecyl sulfate (SDS) sedimentation volume and mixograph behavior) have also been assessed. The study has identified six novel glutenin alleles plus some other rare alleles some of which have been associated with improved durum wheat quality. Most of the novel variation detected needs to be characterized in a wider sample of varieties to establish any eventual beneficial effect on functional quality. Further analysis of the quality properties associated to specific allele combinations of $G l u-A 3, G l u-B 3$, and $G l u-A 1$ has disclosed some clues on the influence on quality of certain non-allelic interactions between these main prolamin-encoding loci. Some of the landraces, showing outstanding values for the gluten quality parameters analyzed, might be directly used by farmers interested in the cultivation of traditional varieties for specialized food markets.
\end{abstract}

Keywords: Triticum turgidum; HMW glutenins; LMW glutenins; gluten quality; non-allelic interactions

\section{Introduction}

Durum wheat (Triticum turgidum L. var. durum) is a self-pollinated allotetraploid cereal $(2 \mathrm{n}=4 \mathrm{x}=28, \mathrm{AABB})$ which shares the genomes A and B with bread wheat. Durum wheat is a traditional Mediterranean crop and one of the pillars of Mediterranean food. Milling of durum wheat grains yields semolina, which is the basis of several products, from Italian pasta, spread throughout the world (spaghetti, macaroni, etc.), to couscous (typical of North African countries), as well as bulgur and breakfast cereals.

Durum wheat was domesticated in the Fertile Crescent 10,000 years before the present (BP), and spread from the east to the west of the Mediterranean Basin [1,2] reaching the Iberian Peninsula around 7000 years BP [3]. Natural and human selection resulted in the establishment of local landraces, specifically adapted to the biotic and abiotic characteristics of their region of origin. From the 1970s of the 20th century, the release of modern breeding varieties, more yielding under conventional crop management systems, led to their progressive abandonment [4]. It has markedly narrowed the genetic diversity present in current varieties of durum wheat as well as of bread wheat $[5,6]$. 
The next-generation of wheat cultivars will have to meet the food demands of an increasing human population while facing the uncertainty of future climate conditions and with less input requirements (water, fertilizers, etc.) as demand for improving the sustainability of agro-ecosystems. Wheat landraces are among the most suitable germplasm resource where the genetic variation required for that aim can be searched. These locally adapted varieties have several advantages over wild wheat relatives as donors for the incorporation of useful traits into elite varieties; firstly, because no crossability or offspring viability problems are expected, and secondly because of the lower risk of co-transferring agronomically unfavorable alleles. It explains that several huge research initiatives have undertaken the characterization of the phenotypic, genetic and genomic diversity of wide collections of landraces (i.e., seedsofdiscovery.org; www.whealbi.eu). The final overall objective of these research efforts is to find allelic variation that can be exploited for the breeding of high-yielding, resilient wheat cultivars with less vulnerability to biotic and abiotic limitations. However, it cannot be forgotten that most of the wheat production is used for human consumption [7]. Grain composition of new bread and pasta wheat cultivars should then maintain appropriate end-use properties of flours and semolinas. It may be therefore advisable that genetic factors associated with improved functional quality are characterized and employed as additional criteria in the selection of local varieties to be used as donor germplasm. Furthermore, the increasing market for food products derived from traditional varieties is likely to trigger a growing commercial interest in landraces with high-quality performance, especially suitable for low-input cropping systems [8].

The endosperm reserve proteins are the most important and studied wheat quality components. This group of proteins constitutes a very heterogeneous material [9], which includes albumins (water-soluble), globulins (soluble in neutral salt solutions) and prolamins of two types: gliadins and glutenins. The association of prolamins with lipids and other components (minerals, carbohydrates) forms a viscoelastic complex called gluten. The specific profile of endosperm proteins of a given wheat cultivar has a direct relationship with bread or semolina quality, is independent of environmental conditions, and depends on relatively few genes, being easily identified by electrophoretic methods. In the case of durum wheat, the most commonly used markers for semolina quality are gliadins $\gamma-42$ and $\gamma-45$. The presence of gliadin $\gamma-45$ was early associated with gluten strength [10], but the effect is really caused by the subunits of low molecular weight (LMW) glutenins tightly linked to gliadin $\gamma-45$ and not by $\gamma-45$ itself [11]. Further studies have indeed established that the functional quality of durum wheat mainly depends on their subunit composition for LMW glutenins, encoded by the Glu-A3, Glu-B3 and Glu-B2 loci [12-14].

Aguiriano and coworkers analyzed the allelic variation for prolamins in a set of 52 Spanish durum wheat landraces, which represented around $10 \%$ of the Spanish durum wheat local varieties maintained in the national germplasm bank [15]. A few other accessions from the whole collection have been included in studies where the prolamin composition of landraces from different Mediterranean countries has been described [16,17]. These studies have evidenced the remarkable variability for prolamins in Spanish accessions, which is far from fully represented in the Spanish core collection of durum wheat [18]. The present study has characterized the prolamin composition of a wide set of Spanish durum wheat landraces. Quality-related parameters routinely used for the preliminary screening of large germplasm samples have also been evaluated. The aims were to identify durum wheat landraces bearing prolamin-coding alleles already associated with good semolina quality and to characterize novel allelic variation as well as allele combinations related to improved durum wheat quality.

\section{Materials and Methods}

\subsection{Plant Material and Field Experimental Design}

A set of 158 Spanish durum wheat landraces (Triticum turgidum L. ssp durum, $2 \mathrm{n}=4 \mathrm{x}=28$, AABB) - from the collection of around 500 maintained at the Plant Genetic Resources Center of the 
National Institute for Agricultural Research and Experimentation of Spain (CRF-INIA; Alcalá de Henares, Madrid) - has been analyzed. None of these accessions had been examined in an earlier study focused on Spanish durum wheat landraces [15].

The materials were sowed by duplicate in plots of three rows $(1.5 \mathrm{~m}$ long) following a random complete block design in the experimental fields of the School of Agricultural, Food and Biosystems Engineering (ETSIAAB, Universidad Politécnica de Madrid; $40^{\circ} 25^{\prime} \mathrm{N}, 3^{\circ} 42^{\prime} \mathrm{W}$ ), in the agricultural years 2011/2012 and 2014/2015. Harvested grains from the replicated plots were mixed prior to conducting the semolina quality analyses.

\subsection{Homogeneity of Landraces}

Five grains per accession were randomly collected and their protein profile (glutenin subunits and gliadins) was analyzed by sodium dodecyl sulfate-polyacrylamide gel electrophoresis (SDS-PAGE). The landraces that resulted to be formed by a mixture of genotypes were not considered for further analyses.

\subsection{Characterization of High and Low Molecular Weight Glutenins, and Gliadins}

High molecular weight (HMW) and LMW glutenins were extracted following the protocol described by [19]. Electrophoresis of reduced and alkylated glutenin proteins was performed on one-dimensional SDS-PAGE at $12 \%$ polyacrylamide [20] and gliadins were fractionated by acid polyacrylamide gel electrophoresis (A-PAGE) [21]. HMW glutenin alleles (Glu-A1 and Glu-B1 loci) were identified using the nomenclature of Payne and Lawrence [22] with some modifications [23], LMW glutenin alleles (Glu-A3, Glu-B3, and Glu-B2 loci) were named following Nieto-Taladriz et al. [24], and $\gamma$-gliadins (Gli-B1 locus) were named according to Kudryavtsev et al. [25].

\subsection{Mass Spectrometry}

The protein of interest was manually extracted from the SDS-PAGE gel and introduced into a $1.5 \mathrm{~mL}$ tube where the protein was reduced, alkylated and digested [26]. After digestion, the supernatant was collected and analyzed in a 4800 Proteomic Analyzer MALDI-TOF/TOF mass spectrometer (Applied Biosystems, Framingham, MA) at the Genomics and Proteomics Center of the Complutense University of Madrid (Madrid, Spain).

\subsection{Semolina Quality Analyses}

Protein content, on a $14 \%$ moisture basis, was estimated by near-infrared reflectance analysis (NIR) using a Technicon Infralyzer 300 (Technicon Instrument Co. Ltd., Hants, UK). The SDS-sedimentation (SDSS) test was performed as described Dick and Quick [27] with the following modifications: two mixing periods of 20 and $10 \mathrm{sec}$ were used, and stoppered tubes were inverted, by means of a mechanical shaker, 16 times in each of two periods of $40 \mathrm{sec}$ with a rest of $2 \mathrm{~min}$ between the two periods [28]. Rheological properties were determined by Mixograph of $10 \mathrm{~g}$ whole wheat meal [29], with modification for a constant water absorption of $6.5 \mathrm{~mL}$. The mixograph parameters were: mixing development time (MT), maximum peak height (MH), height at 3 min after the peak (H3), and resistance to breakdown (BDR) which is the percentage difference between $\mathrm{MH}$ and $\mathrm{H} 3$.

\subsection{Statistical Analyses}

Analysis of variance and Duncan's method for multiple mean comparisons were used to study the effects on the quality parameters of the allelic variation encoded by the glutenin and gliadin loci examined, and the effect of year $(E)$ and genotype $\times$ year $(G \times E)$ interactions in the case of parameters measured in 2012 and 2015 samples. Multivariate analysis with principal component analyses (PCA) was applied to analyze the relationships between the quality variables and allelic variants or allele combinations at selected loci. Relations between variables were estimated by Pearson correlation 
coefficients. All statistical analyses were completed with the InfoStat statistical package (Faculty of Agricultural Sciences of the National University of Córdoba, Córdoba, Argentine) [30].

\section{Results and Discussion}

Local varieties are usually formed by a mixture of genotypes [31]. Within our initial set of 158 Spanish landraces, 116 accessions showed homogeneous electrophoretic patterns. The remaining accessions $(26.7 \%)$ were heterogeneous for at least one of the prolamins analyzed. Such a level of intrapopulation variability is similar to that found by other authors in Spanish local populations $(28 \%$; [32]) and in Algerian landraces (20\%; [33]).

The germplasm bank codes and local names of these 116 accessions selected for further characterization are given in Supplementary Table S1. It includes also their alleles or subunits for each prolamin-encoding locus analyzed and values for the quality parameters examined. Passport and characterization data on each of the entries can be retrieved from the INIA-CRF germplasm database (www.inia.es).

\subsection{Characterization of Prolamin Loci}

Table 1 shows the glutenin subunits that were observed in the durum wheat landraces at Glu-A1, Glu-B1, Glu-A3, Glu-B3, and Glu-B2 loci, and the $\gamma$-gliadins at the Gli-B1 locus.

Table 1. Frequency of the different high molecular weight (HMW) and low molecular weight (LMW) glutenin subunits and $\gamma$-gliadins observed for loci Glu-1, Glu-3, Glu-B2, and Gli-B1 in the 116 durum wheat landraces analyzed. The allele correspondence is indicated for those variants that have been already designated.

\begin{tabular}{|c|c|c|c|c|}
\hline Locus & Allele & Prolamin Subunits & No. & $\%$ \\
\hline \multirow{5}{*}{$\begin{array}{c}\text { Glu-A1 } \\
\text { (HMW glutenins) }\end{array}$} & $a$ & 1 & 24 & 20.7 \\
\hline & $b$ & $2^{*}$ & 27 & 23.3 \\
\hline & $c$ & Null & 60 & 51.7 \\
\hline & $o$ & $\mathrm{~V}$ & 4 & 3.4 \\
\hline & - & new & 1 & 0.9 \\
\hline \multirow{9}{*}{$\begin{array}{c}\text { Glu-B1 } \\
\text { (HMW glutenins) }\end{array}$} & $a$ & 7 & 2 & 1.7 \\
\hline & $b$ & $7+8$ & 13 & 11.2 \\
\hline & $e$ & $20 x+20 y$ & 20 & 17.2 \\
\hline & $f$ & $13+16$ & 11 & 9.5 \\
\hline & an & 6 & 2 & 1.7 \\
\hline & $a q$ & $32+33$ & 8 & 6.9 \\
\hline & $b d$ & $20 x+8$ & 1 & 0.9 \\
\hline & - & $20 x$ & 1 & 0.9 \\
\hline & - & $6+(8)$ & 58 & 50.0 \\
\hline \multirow{12}{*}{$\begin{array}{c}\text { Glu-A3 } \\
\text { (LMW glutenins) }\end{array}$} & $a$ & 6 & 47 & 40.5 \\
\hline & $b$ & 5 & 9 & 7.8 \\
\hline & $d$ & $6+11$ & 3 & 2.6 \\
\hline & $e$ & 11 & 9 & 7.8 \\
\hline & $h$ & Null & 35 & 30.2 \\
\hline & $q$ & $5+20$ & 3 & 2.6 \\
\hline & $i$ & $8^{*}+11$ & 1 & 0.9 \\
\hline & - & $5^{*}$ & 1 & 0.9 \\
\hline & - & $8^{*}$ & 3 & 2.6 \\
\hline & - & $5+8^{*}$ & 3 & 2.6 \\
\hline & - & $5^{*}+20$ & 1 & 0.9 \\
\hline & - & $6+20$ & 1 & 0.9 \\
\hline
\end{tabular}


Table 1. Cont.

\begin{tabular}{|c|c|c|c|c|}
\hline Locus & Allele & Prolamin Subunits & No. & $\%$ \\
\hline \multirow{16}{*}{$\begin{array}{c}\text { Glu-B3 } \\
\text { (LMW glutenins) }\end{array}$} & $a$ & $2+4+15+19$ & 44 & 37.9 \\
\hline & $b$ & $8+9+13+16$ & 4 & 3.4 \\
\hline & $d$ & $2+4+15+17+19$ & 2 & 1.7 \\
\hline & $e$ & $2+4+15+16+18$ & 3 & 2.6 \\
\hline & $f$ & $2+4+15+17$ & 14 & 12.0 \\
\hline & $g$ & $2+4+15+16$ & 1 & 0.9 \\
\hline & $h$ & $1+3+14+18$ & 18 & 15.5 \\
\hline & $i$ & $5+7+8+14+18$ & 16 & 13.8 \\
\hline & - & $1+3+13^{*}+19$ & 1 & 0.9 \\
\hline & - & $1+3+13+19$ & 1 & 0.9 \\
\hline & - & $13^{*}+18$ & 1 & 0.9 \\
\hline & - & $13^{*}+15+19$ & 3 & 2.6 \\
\hline & - & $13+14+18$ & 1 & 0.9 \\
\hline & - & $13+19$ & 4 & 3.4 \\
\hline & - & $2+4+13+15+17$ & 1 & 0.9 \\
\hline & - & $2+4+13+16+19$ & 2 & 1.7 \\
\hline \multirow{3}{*}{$\begin{array}{c}\text { Glu-B2 } \\
\text { (LMW glutenins) }\end{array}$} & $a$ & 12 & 58 & 50.0 \\
\hline & $b$ & Null & 55 & 47.4 \\
\hline & $c$ & $12^{*}$ & 3 & 2.6 \\
\hline \multirow{9}{*}{$\begin{array}{c}\text { Gli-B1 } \\
(\gamma \text {-gliadins })\end{array}$} & & Null & 9 & 7.8 \\
\hline & & $\gamma-40$ & 1 & 0.9 \\
\hline & & $\gamma-41$ & 2 & 1.7 \\
\hline & & $\gamma-42$ & 4 & 3.4 \\
\hline & & $\gamma-43$ & 2 & 1.7 \\
\hline & & $\gamma-44$ & 21 & 18.1 \\
\hline & & $\gamma-45$ & 75 & 64.6 \\
\hline & & $\gamma-46$ & 1 & 0.9 \\
\hline & & $\gamma-47$ & 1 & 0.9 \\
\hline
\end{tabular}

\subsubsection{HMW Glutenin Subunits}

Five alleles encoded by the Glu-A1 locus could be identified (Table 1). Three of them (namely $a, b$ and $c$ ) are common alleles already described by Payne and Lawrence [22]. The most frequent was the $c$ allele (null allele) found in 60 landraces (51.7\%), while alleles $a$ and $b$ (subunits 1 and $2^{*}$ ) were found in 24 and 27 landraces, respectively (20.7\% and 23.3\%). Aguiriano and coworkers reported a quite similar frequency of the $a$ and $c$ Glu-A1 alleles (33\% and 38\%, respectively) in a sample of 52 Spanish landraces [15]. The present results are based on a larger sample and hence can be considered more representative of the allelic richness of Spanish durum wheat local varieties. Several other studies have found a frequency of $c$ allele even higher than 50\% in Mediterranean landraces (i.e., [16,17,32,34-36]).

The rare $o$ allele (V subunit) was found in four landraces (3.4\%). This allele, also designated as $2^{* *}$, was early described in two Portuguese local varieties of durum wheat [37] and in five varieties within a collection of 502 durum wheat accessions from a wider geographical origin [38]. Three later studies conducted on Mediterranean landraces reported the presence of this allele although always at the lowest frequency $[15,17,36]$. It can be highlighted that this allele is not among the represented in the Spanish core collection of durum wheat [18]. Additionally, a novel HMW subunit with a higher electrophoretic mobility than the V subunit was identified in the accession BGE19307 ('Baza'; Figure 1a). 
a)

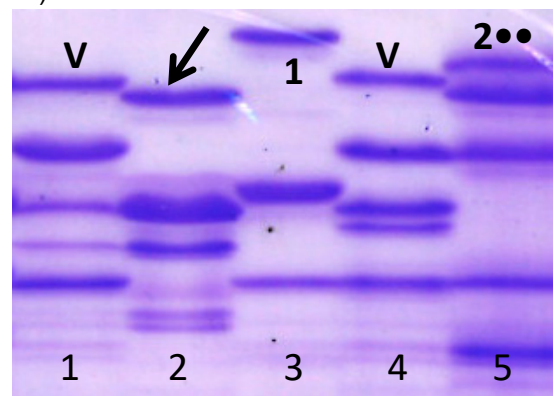

b)

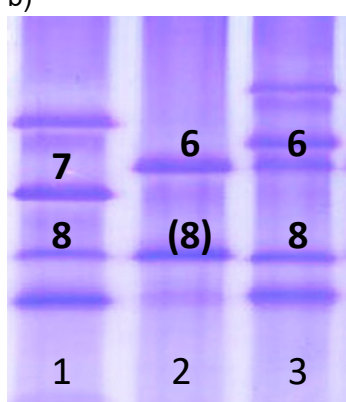

c)

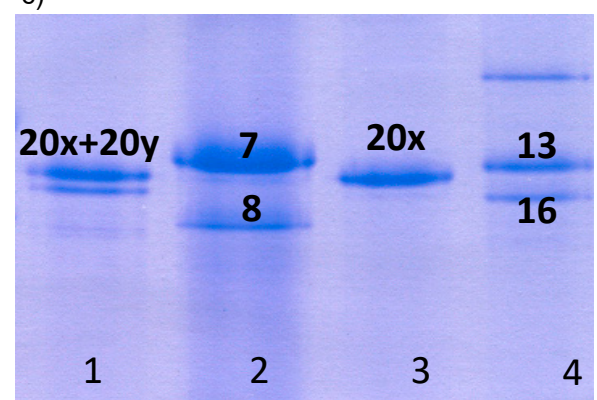

Figure 1. Electrophoretic patterns of durum wheat landraces and standard varieties illustrating some of the high molecular weight glutenin subunits (HMW-GS) observed in the accessions under study. (a) Lanes 1-5 show the subunits encoded by the Glu-A1 locus in accessions BGE018295, BGE019307 (new subunit), BGE013104 and BGE018273, and in the standard bread wheat 'Ribeiro', respectively. The HMW-GS not previously described is indicated by an arrow. (b) Prolamin bands encoded by the Glu-B1 locus in the bread wheat standards for the subunit pairs $7+8$ ('Chinese Spring', lane 1) and 6+8 ('Hope', lane 3) and in one durum wheat accession with the By(8) subunit (BGE-018315, lane 2). (c) Lanes 1-4 show the subunits encoded by the Glu-B1 locus in 'Federation', 'Chinese Spring', landrace BGE021769 (Bx20 subunit) and 'Lancota', respectively.

The Glu-B1 locus was the most polymorphic HMW locus (Table 1). Seven previously cataloged alleles were found, namely $a, b, e, f, a n, a q$ and $b d$ [23]. Among them, $e, b, f$ and $a q$ alleles were the most frequent $(17.2 \%, 11.2 \%, 9.5 \%$, and $6.9 \%$ respectively). A quite similar allele composition has been found by other authors in Spanish [32] and Portuguese germplasm [34,39]. The 6+(8) pair, a subunit combination with no allele designation, was the most frequent (Table 1). The subunit named (8) has been previously observed in durum wheat [36] and bread wheat [40]. It shows a slightly different mobility than the By8 present in the pairs $6+8$ and $7+8$ of the bread wheat standards 'Hope' and 'Chinese Spring', respectively (Figure 1b).

A single protein band with a similar electrophoretic mobility than the Glu-B1x subunit of the $20 x+20 y$ pair was observed in one accession (BGE021769; Figure 1c). This finding was quite unexpected since the presence of the 20x subunit alone had only been described in a Portuguese local variety of common wheat [41]. To confirm its identity, the protein was extracted and analyzed by matrix-assited laser desorption/ionization time-of-flight (MALDI-TOF) mass spectrometry (see Supplementary Figure S1). It can be noted that the core collection of Spanish durum wheat includes a line derived from the landrace analyzed here, as representative of this rare Glu-B1 allele (BGE045673; see [18]).

\subsubsection{LMW Glutenin Subunits}

The analysis of glutenin subunits encoded by the Glu-A3 locus revealed seven alleles $(a, b, d, e, h$, $q, i)$ previously cataloged $[24,42,43]$. The $a$ allele was the most frequent $(40.5 \%$; Table 1$)$. The high frequency of this good quality-related allele in durum wheat materials agrees with the findings reported in commercial varieties [24] and in local varieties of Portugal, Algeria and Spain [15,33,39]. Also in agreement to earlier results $[17,33]$, the $h$ null-allele has been the second most frequent $(30.2 \%)$. The allele $q$ (pair $5+20$ ), found in four local varieties, has been formerly reported in local germplasm (i.e., [33]).

In addition to those already cataloged, two subunits $\left(5^{*}\right.$ and $\left.8^{*}\right)$ and three pairs of subunits $\left(5+8^{*}\right.$, $5^{*}+20$ and $6+20$ ) with no allele correspondence were found in our study. Among them, the pair $5+8^{*}$ was the only not previously described (Figure 2a, lane 1). This Glu-A3 allele is not represented in the Spanish core collection of durum wheat [18] in spite that its frequency cannot be considered negligible (Table 1). The subunit $5 *$ (Figure $2 b$ ), characterized by a lower mobility than the subunit 5 present in the standard 'Langdon' [24], has been described in other Spanish durum wheat landraces [15,36]. 
The subunit $8^{*}$ (Figure 2a, lane 3) was described in the Portuguese durum wheat 'Mourisco Fino' as part of the pair $8^{*}+11$ [42]. This subunit was subsequently found in Algerian durum wheat [33] and in accessions of T. turanicum [44]. Finally, the pairs $5^{*}+20$ and $6+20$, in only one accession each, have been previously reported in Spanish and Mediterranean durum wheat local landraces, respectively [15,17].

a)

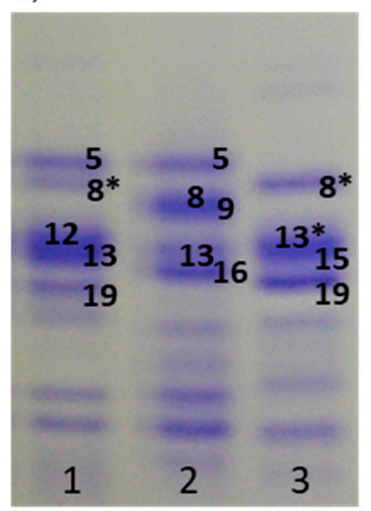

b)

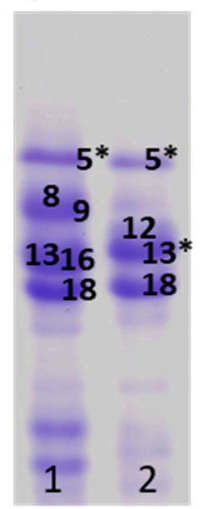

Figure 2. Electrophoretic patterns of durum wheat landraces and standard varieties illustrating some of the low molecular weight glutenin subunits (LMW-GS) observed in the accessions under study. (a) Accessions BGE013718 and BGE019300 (lanes 1 and 3) and standard durum wheat 'Langdon' (lane 2).

(b) Standard durum wheat 'Fanfarron' (lane 1) and accession BGE018657 (lane 2).

The Glu-B3 locus was the most polymorphic among all prolamin loci analyzed, with up to 16 different subunit combinations (Table 1). The highest frequency of the $a$ allele (37.9\%) agrees with all previous reports on Mediterranean durum wheat landraces (e.g., $[15,33,45]$ ), although it is worthy of noting that this allele is even more abundant in commercial varieties of durum wheat [17]. The relatively high presence of the $h$ and $i$ alleles (15.5\% and $13.8 \%$, respectively) is in agreement with the observed by Aguiriano and coworkers [15]. But this feature might be characteristic of Spanish landraces since these alleles are either absent or present at much lower frequency in wide germplasm collections from Portugal [45] and other Mediterranean regions [17]. Moragues and coworkers found a quite relevant frequency of the Glu-B3c allele (27\%) within the set of 26 landraces from the Iberian Peninsula included in their study, which covered accessions from 13 Mediterranean countries [16]. However, this allele, described in commercial varieties of durum wheat [24,45], has been found neither in this work nor in those of other authors that have examined landraces from Spain and Portugal $[15,39]$.

Among the eight combinations of LMW glutenin subunits encoded by the Glu-B3 locus that have no allele designation, four of them had not been described until now: $1+3+13+19,13^{*}+18$ (Figure $2 b$ ), $13+14+18$, and $2+4+13+15+17$ (Table 1 ). Furthermore, the combination $1+3+13^{*}+19$ is the only represented in the Spanish durum wheat core collection [18].

The Glu-B2 locus encoded for three allelic variants, namely $a, b$ and $c$ (Table 1 ). The $a$ and $b$ alleles (subunit 12 and null allele, respectively; see Figure 2) were present each in almost half of the landraces, while the $c$ allele (subunit $12^{*}$ ) was identified in only three out of the 116 accessions. This allele was initially observed in the local variety 'Alcalá la Real' [43] but has not been found in later analyses on wide collections of Mediterranean durum wheat landraces. The relative frequency of the $a$ and $b$ alleles greatly varies between studies, some of them reporting a majority of $a$ alleles (e.g., [24,33,45]), a majority of $b$ alleles (e.g., $[15,17])$ or, as found in this study, a quite similar abundance of both alleles [16].

\subsubsection{Gliadins}

Three of the commonest $\gamma$-gliadin variants encoded by the Gli-B1 locus $(\gamma-42, \gamma-44$, and $\gamma-45)$ were found in the durum wheat landraces examined, but other five rare $\gamma$-gliadins were also observed, and nine accessions did not express any $\gamma$-gliadin (Table 1 ; see Figure 3). Gliadin $\gamma$ - 45 was the most frequent $(64.6 \%)$, which is in coincidence with previous studies carried out in local varieties $[15,32,34,36,46]$ 
as well as in commercial varieties [24,25,28] of durum wheat. Gliadin $\gamma-44$ was present in $18 \%$ of the landraces. This gliadin, that has been found with an even greater frequency in some studies on Spanish landraces $[15,46]$, is practically absent in commercial varieties $[24,25,28]$. The low frequency of the $\gamma-42$ gliadin $(3.4 \%$ of the accessions) is quite in agreement with its representation in the core collection of Spanish durum wheats $(5.3 \%$; [18]). It can be noted that three of the rare variants found here $(\gamma-41$, $\gamma-43$, and $\gamma-46)$ are also represented in the core collection. Among the remainder, $\gamma-40$ and $\gamma-47$, only the former had earlier been reported.

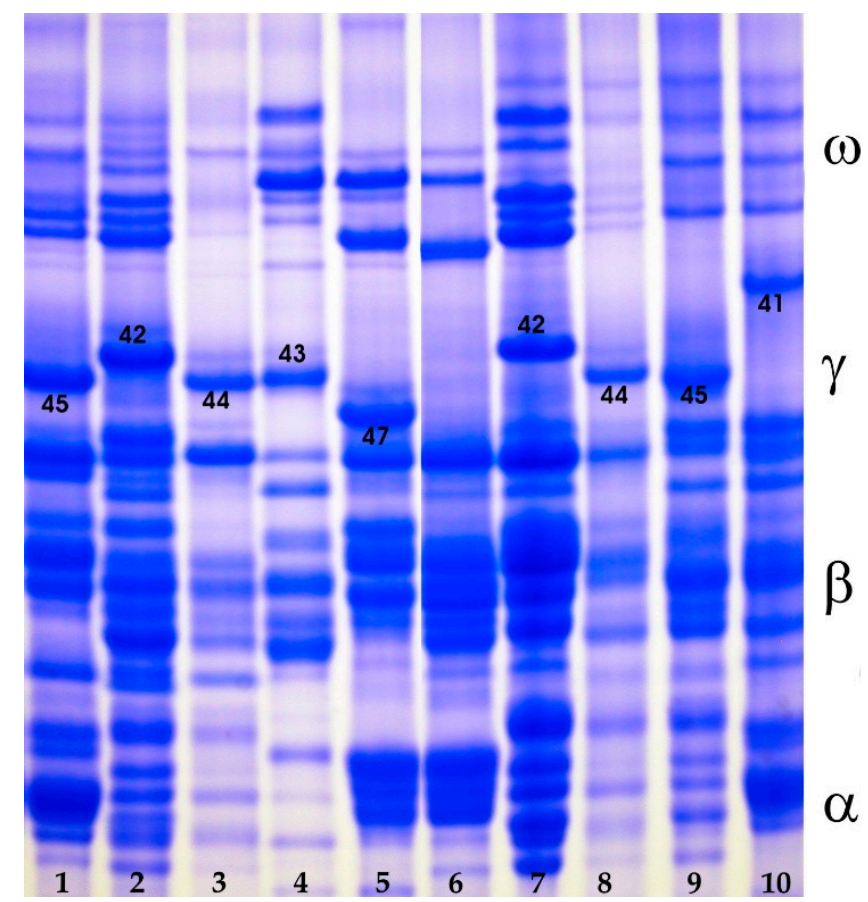

Figure 3. The $\gamma$-gliadin variants detected by acid polyacrylamide gel electrophoresis (A-PAGE) in the durum wheat landraces BGE002879 (1), BGE012334 (2), BGE013098(3), BGE018655 (4), BGE018311 (5), BGE019280 (6) and BGE019290 (10), and in the standard varieties 'Jabato' (7), 'Alaga' (8) and 'Ardente' (9).

\subsection{Quality Evaluation}

\subsubsection{Mean Values, Range of the Quality Tests and Relation Between Quality Parameters}

The mean protein content of the collection was similar in the two years analyzed (14.5\%), ranging from $11.6 \%$ to $16.4 \%$ in the samples of 2011/2012 (2012 data) and from $11.3 \%$ to $17.5 \%$ in $2014 / 2015$ (2015 data). The correlation coefficient between the values recorded in 2012 and 2015 was low but highly significant $(r=0.38, p \leq 0.001)$. The protein content of durum wheat varieties is of critical importance in the pasta industry. It must exceed $13 \%$ to assure the minimum concentration of $12 \%$ required for suitable semolina and pasta processing [47]. It can be highlighted that half of the landraces under study (57 out of 116) showed a protein concentration consistently higher than 14\%, and 18 of them reached above $15 \%$ in both years of analysis (Supplementary Table S1).

The average SDSS volume in flours of 2012 was $29.6 \mathrm{~mm}$, with a wide range (13.0 to $80.0 \mathrm{~mm}$ ), while the mean SDSS value in 2015 samples was $35.3 \mathrm{~mm}$ and the minimum and maximum values were $19 \mathrm{~mm}$ and $87.5 \mathrm{~mm}$, respectively (Table S1). The correlation coefficient between SDSS values recorded in both years was positive and highly significant $(r=0.74, p \leq 0.001)$, as occurred for protein content. Mixograph parameters were determined only in flour samples of 2012. Mean values of MT (mixing development time) and BDR (resistance to breakdown) were $56.5 \mathrm{~s}$ and 31.9\%, respectively. These parameters, related to the mechanical properties of wheat doughs, had again wide-ranging 
values in the collection of landraces examined, i.e., 18.0 to $129.0 \mathrm{~s}$ (MT) and 6.7 to $47.2 \%$ (BDR) (see Supplementary Table S1). Good gluten properties are associated with high values for SDSS and MT, and low BDR. As then expected, the correlation between SDSS values and the mixograph parameters was highly significant and positive with MT $(r=0.83, p<0.001)$ while negative with BDR $(r=-0.57$, $p<0.001)$, and MT and BDR were negatively correlated $(r=-0.66, p<0.001)$. These results on the inter-relation between SDSS, MT and BDR values are similar to the reported in earlier studies (e.g., [48,49]. Also, in agreement with those and other authors (e.g., [36]), no significant correlation was detected between protein content and SDSS or MT values (see Supplementary Table S2), while a significant positive relation of protein content with BDR was found $(r=0.35, p<0.001)$.

\subsubsection{Effect of Allelic Variation at Individual Prolamin Loci}

Analysis of variance (ANOVA) tests were conducted to determine the effect of allelic variation at the prolamin loci on protein content and gluten quality parameters. Alleles that had been found in less than three accessions were excluded from these analyses. For protein content and SDSS, the effects of the year and the genotype $\times$ year were also determined. Since no significant genotype $x$ year interactions were detected (see Supplementary Table S3), repeated ANOVA tests that excluded this source of variation were conducted. The results are summarized in Table 2, which also shows the mean values obtained for the distinct alleles at each locus after Duncan's multiple comparison tests.

Protein content was the trait less significantly influenced by the variability at the loci analyzed, a certain effect is associated with allelic variation at Glu-B1 and Glu-B3 alleles. The Duncan's test detected differences between landraces presenting distinct alleles at Glu-A3 despite the effect of this locus on protein content was not significant according to the ANOVA test. As expected, a greater effect of the genotypic factors was obtained for the variables related to the functional properties of gluten, i.e., SDSS, MT and BDR. Allelic variation at Glu-A1, Glu-A3 and Glu-B3 affected SDSS, and significant differences for SDSS mean values were obtained between alleles of all loci examined except Glu-B2 (Table 2). MT was influenced by variation at Glu-A1 and Glu-A3. BDR was especially influenced by variation at $G l u-A 1$ and, to a lesser extent, at Glu-A3 and Glu-B3, although mean differences depending on the Glu-B1 allele present were also obtained.

Among the four Glu-A1 alleles whose effect could be analyzed, the allele Glu-A1o (subunit V) showed a highly significant positive effect on gluten properties, associated with the highest values for SDSS and TM, and the lowest for BDR. This allele was found in four of the 116 landraces under study, none of which could be examined in the second year of analysis. Certain evidences, however, support the interest of conducting further studies to confirm its beneficial influence on wheat quality. So, the landraces that presented this allele (BGE018265, BGE018270, BGE018284, and BGE018285) have maintained high SDSS values (53-77 $\mathrm{mm}$ ) in samples from other seasons than the reported here. Additionally, Babay and coworkers described this allele in two landraces, one from Algeria and the other from Spain, that showed overall good gluten properties according to their SDSS, MT and BDR values [36]. No significant differences were detected on the quality-related traits between the remaining GluA1 alleles (Table 2). To some extent, this finding could result from the much greater effect of the allele $o$, although a similar influence of alleles $a, b$ and $c$ agrees with the reported in other studies [50,51].

Allelic variation at the HMW locus Glu-B1 was less relevant than at Glu-A1 (Table 2). Landraces bearing the allele $b$ (subunits 7+8) showed high SDSS and MT values, in agreement with the findings by other authors in commercial varieties of durum wheat $[28,50,51]$. It can also be noted the good mixograph parameters of the accessions with the Glu-B1f allele $(13+16)$. This allele is very infrequent in commercial varieties which explain the scarce number of studies that have analyzed its effect on quality. Nevertheless, its presence in a durum wheat variety showing high gluten strength and tenacity has been reported [50]. 
Table 2. ANOVA F-values testing the effect of the prolamin loci on the quality traits analyzed. The effect of the year is also considered for protein content and SDS sedimentation volume. The results of the Duncan's multiple comparison of means are included.

\begin{tabular}{|c|c|c|c|c|c|}
\hline $\begin{array}{l}\text { Source of } \\
\text { Variation }\end{array}$ & Allele/Subunits & Protein $(\%)$ & SDSS (mm) & MT (s) & BDR (\%) \\
\hline \multirow{4}{*}{ Glu-A1 } & $a(1)$ & $14.7 \pm 0.2^{\mathrm{a}}$ & $34.7 \pm 1.7^{b}$ & $55.6 \pm 4.2^{b}$ & $35.3 \pm 1.4^{\mathrm{a}}$ \\
\hline & $b\left(2^{*}\right)$ & $14.4 \pm 0.2^{a}$ & $27.3 \pm 1.7^{b}$ & $45.5 \pm 4.8^{b}$ & $35.1 \pm 1.5^{\mathrm{a}}$ \\
\hline & $c$ (null) & $14.6 \pm 0.1^{a}$ & $28.6 \pm 1.1^{b}$ & $57.5 \pm 2.6^{b}$ & $30.2 \pm 0.9^{a}$ \\
\hline & $o(\mathrm{~V})$ & $13.9 \pm 0.5^{a}$ & $60.4 \pm 4.8^{\mathrm{a}}$ & $99.8 \pm 8.6^{\mathrm{a}}$ & $21.7 \pm 2.9^{b}$ \\
\hline$F$-value ${ }^{\#}$ & & 2.10 & $15.3^{* * *}$ & $11.0^{* * *}$ & $12.1^{* * *}$ \\
\hline \multirow{5}{*}{ Glu-B1 } & $b(7+8)$ & $14.0 \pm 0.3^{b}$ & $38.8 \pm 2.5^{\mathrm{a}}$ & $63.5 \pm 6.1^{a}$ & $31.9 \pm 2.1^{\mathrm{ab}}$ \\
\hline & $e(20 \mathrm{x}+20 \mathrm{y})$ & $14.8 \pm 0.2^{\mathrm{a}}$ & $25.8 \pm 1.7^{c}$ & $54.8 \pm 4.2^{\mathrm{a}}$ & $31.2 \pm 1.4^{\mathrm{ab}}$ \\
\hline & $f(13+16)$ & $14.6 \pm 0.3^{\mathrm{ab}}$ & $32.1 \pm 2.4^{b}$ & $62.4 \pm 5.6^{\mathrm{a}}$ & $29.1 \pm 1.9^{a b}$ \\
\hline & $a q(32+33)$ & $14.5 \pm 0.3^{a b}$ & $26.5 \pm 2.4^{\mathrm{c}}$ & $55.6 \pm 6.2^{\mathrm{a}}$ & $28.2 \pm 2.1^{b}$ \\
\hline & $6+(8)$ & $14.6 \pm 0.1^{\mathrm{ab}}$ & $33.5 \pm 1.2^{\mathrm{ab}}$ & $56.5 \pm 2.9^{a}$ & $33.9 \pm 1.0^{\mathrm{a}}$ \\
\hline$F$-value & & $2.84 *$ & 1.58 & 0.23 & 2.24 \\
\hline \multirow{8}{*}{ Glu-A3 } & $a(6)$ & $14.6 \pm 0.1^{\mathrm{abc}}$ & $34.2 \pm 1.2^{\mathrm{ab}}$ & $64.1 \pm 3.0^{\mathrm{a}}$ & $28.9 \pm 1.0^{b}$ \\
\hline & $b(5)$ & $15.5 \pm 0.5^{\mathrm{a}}$ & $27.0 \pm 4.8^{\mathrm{bcd}}$ & $58.5 \pm 12.1^{a b}$ & $34.3 \pm 4.1^{\mathrm{ab}}$ \\
\hline & $d(6+11)$ & $15.1 \pm 0.4^{\mathrm{ab}}$ & $19.0 \pm 4.8^{\mathrm{d}}$ & $33.0 \pm 12.1^{b}$ & $40.4 \pm 4.1^{\mathrm{a}}$ \\
\hline & $e(11)$ & $13.8 \pm 0.3^{c}$ & $19.7 \pm 2.5^{\mathrm{cd}}$ & $37.3 \pm 6.3^{\mathrm{ab}}$ & $35.1 \pm 2.1^{\mathrm{ab}}$ \\
\hline & $h$ (null) & $14.5 \pm 0.1^{\mathrm{abc}}$ & $31.0 \pm 1.3^{b c}$ & $56.4 \pm 3.3^{\mathrm{ab}}$ & $32.8 \pm 1.1^{\mathrm{ab}}$ \\
\hline & $q(5+20)$ & $14.3 \pm 0.5^{a b c}$ & $30.5 \pm 4.7^{\mathrm{bcd}}$ & $48.0 \pm 12.1^{\mathrm{ab}}$ & $36.0 \pm 4.1^{\mathrm{ab}}$ \\
\hline & $8^{*}$ & $14.3 \pm 0.5^{a b c}$ & $30.5 \pm 4.3^{b c}$ & $64.6 \pm 10.4^{\mathrm{a}}$ & $30.6 \pm 3.5^{\mathrm{ab}}$ \\
\hline & $5+8^{*}$ & $13.9 \pm 0.5^{b c}$ & $43.3 \pm 4.7^{\mathrm{a}}$ & $66.0 \pm 12.1^{a}$ & $31.3 \pm 4.1^{\mathrm{ab}}$ \\
\hline$F$-value & & 1.91 & $3.73 * *$ & $3.44^{* *}$ & $2.84 *$ \\
\hline \multirow{8}{*}{ Glu-B3 } & $a(2+4+15+19)$ & $14.5 \pm 0.1 \mathrm{ab}$ & $35.2 \pm 1.2^{a b}$ & $64.9 \pm 2.9^{a}$ & $28.8 \pm 1.0^{b c}$ \\
\hline & $b(8+9+13+16)$ & $14.3 \pm 0.4^{\mathrm{ab}}$ & $26.6 \pm 3.3^{b}$ & $54.0 \pm 8.6^{\mathrm{a}}$ & $32.8 \pm 2.9^{a b c}$ \\
\hline & $e(2+4+15+16+18)$ & $14.6 \pm 0.5^{\mathrm{ab}}$ & $28.9 \pm 4.8^{\mathrm{ab}}$ & $64.5 \pm 12.1^{\mathrm{a}}$ & $24.2 \pm 4.1^{\mathrm{c}}$ \\
\hline & $f(2+4+15+17)$ & $14.1 \pm 0.3^{\mathrm{ab}}$ & $27.5 \pm 2.4^{b}$ & $50.0 \pm 5.3^{a}$ & $33.8 \pm 1.8^{\mathrm{ab}}$ \\
\hline & $h(1+3+14+18)$ & $15.0 \pm 0.2^{\mathrm{a}}$ & $27.3 \pm 1.9^{b}$ & $53.4 \pm 4.6^{\mathrm{a}}$ & $33.9 \pm 1.6^{\mathrm{ab}}$ \\
\hline & $i(5+7+8+14+18)$ & $15.1 \pm 0.3^{\mathrm{a}}$ & $27.9 \pm 2.4^{\mathrm{ab}}$ & $50.2 \pm 6.4^{\mathrm{a}}$ & $36.7 \pm 2.1^{\mathrm{ab}}$ \\
\hline & $13^{*}+15+19$ & $13.7 \pm 0.5^{b}$ & $38.3 \pm 4.7^{\mathrm{a}}$ & $63.0 \pm 12.1^{\mathrm{a}}$ & $30.5 \pm 4.1^{\mathrm{abc}}$ \\
\hline & $13+19$ & $14.4 \pm 0.5^{\mathrm{ab}}$ & $36.1 \pm 4.7^{\mathrm{ab}}$ & $49.5 \pm 12.1^{\mathrm{a}}$ & $39.2 \pm 4.1^{\mathrm{a}}$ \\
\hline \multirow[t]{2}{*}{$F$-value } & & $2.17^{*}$ & $2.22 *$ & 1.36 & $2.22 *$ \\
\hline & $a(12)$ & $14.3 \pm 0.1^{a}$ & $33.0 \pm 1.2^{\mathrm{a}}$ & $60.2 \pm 2.9^{a}$ & $29.6 \pm 1.0^{a}$ \\
\hline \multirow[t]{2}{*}{ Glu-B2 } & $b$ (null) & $14.7 \pm 0.1^{\mathrm{a}}$ & $30.8 \pm 1.2^{\mathrm{a}}$ & $55.7 \pm 2.8^{a}$ & $33.7 \pm 1.0^{\mathrm{a}}$ \\
\hline & $c\left(12^{*}\right)$ & $14.2 \pm 0.5^{\mathrm{a}}$ & $29.4 \pm 4.2^{\mathrm{a}}$ & $54.0 \pm 9.9^{a}$ & $35.1 \pm 3.3^{a}$ \\
\hline \multirow[t]{2}{*}{$F$-value } & & 2.13 & 0.31 & 0.22 & 1.54 \\
\hline & $\gamma-42$ & $14.3 \pm 0.4^{\mathrm{a}}$ & $26.6 \pm 3.3^{b}$ & $54.0 \pm 8.6^{\mathrm{a}}$ & $32.8 \pm 2.9^{a}$ \\
\hline \multirow[t]{2}{*}{ Gli-B1 } & $\gamma-44$ & $14.7 \pm 0.2^{\mathrm{a}}$ & $29.2 \pm 1.6^{\mathrm{ab}}$ & $51.6 \pm 4.1^{\mathrm{a}}$ & $34.6 \pm 1.4^{\mathrm{a}}$ \\
\hline & $\gamma-45$ & $14.5 \pm 0.1^{a}$ & $33.7 \pm 1.0^{\mathrm{a}}$ & $60.3 \pm 2.4^{\mathrm{a}}$ & $30.7 \pm 0.8^{a}$ \\
\hline$F$-value & & 0.11 & 0.29 & 0.18 & 0.29 \\
\hline \multirow{2}{*}{ Year } & 2012 & $14.5 \pm 0.1^{a}$ & $29.6 \pm 1.1^{b}$ & $56.1 \pm 2.0$ & $31.9 \pm 0.7$ \\
\hline & 2015 & $14.5 \pm 0.1^{a}$ & $35.3 \pm 1.2^{\mathrm{a}}$ & & \\
\hline$F$-value & & 0.11 & $7.05 * *$ & & \\
\hline
\end{tabular}

SDSS—sodium dodecyl sulphate sedimentation volume; MT—mixing time; BDR—breakdown resistance. Mean values followed by different letters are significantly different $(p=0.05)$. ${ }^{\#}:{ }^{*} 0.05>p>0.01$; ${ }^{* *} 0.01>p>0.001$; $* * * p<0.001$. 
Regarding the LMW Glu-A3 locus, the effect of six designated alleles and the subunits $8^{*}$ and $5+8^{*}$ could be analyzed (Table 2 ). A clear deleterious effect on gluten properties was found for allele $d$ $(6+11)$, which resulted in the lowest SDSS and MT values and the highest BDR among all recorded. This result was unexpected since a positive influence of this allele on SDSS values has been reported in commercial varieties and Mediterranean landraces [17,51]. The small sample of landraces where this allele was found makes it difficult to further analyze whether the specific alleles present at other prolamin-encoding loci may be responsible for such disagreement. Landraces bearing the $5+8^{*}$ pair had the highest SDSS and MT values, and a positive influence of the subunit $8^{*}$ on MT was also found. Even only three landraces presented each of them, these results can be highlighted since there is no previous report on the influence of these two Glu- $A 3$ allelic patterns on dough rheological properties.

As occurred for Glu-A3, allelic variation at the LMW locus Glu-B3 was found to be relevant for rheological properties. Landraces with subunits $13^{*}+15+19,13+19$ and allele $a$ had the best SDSS values. Their effect on mixograph parameters was, however, quite contrasting. Subunit combination $13^{*}+15+19$ and allele $a$ showed the highest MT values, although the means were not significantly different, and the allele $a$ maintained a positive effect on quality as indicated by lower BDR values. However, the low MT and high BDR values found for the pair 13+19 are associated with worse gluten behavior (Table 2). It can be noted that the presence of the Glu-B3a allele has already been recognized as a prerequisite of functional quality of durum wheat $[14,43,51]$, but the influence of the other LMW subunit combinations had not been reported earlier.

No significant effect on any of the gluten quality-related parameters examined was found to be associated with allelic variation at either Glu-B2 and Gli-B1 loci, although mean SDSS value of landraces bearing gliadin $\gamma-45$ was higher than in landraces with gliadin $\gamma-42$. It is worthy of noting that these two $\gamma$-gliadins have been traditionally used as markers of, respectively, good and bad processing properties in durum wheat because of the tight genetic linkage between Gli-1 and Glu-3 loci [11,52].

Many studies have established that the gluten strength of durum wheats ultimately depends on their subunit composition for LMW glutenins, encoded by the Glu-A3, Glu-B3 and Glu-B2 loci [11,53], whereas a lesser effect has been demonstrated for HMW-GS [12-14,54]. However, the findings reported above demonstrate no influence of $G l u-B 2$ and a relevant effect of $G l u-A 1$ in the set of Spanish landraces examined. Figure 4 shows the results of a multivariate PCA analysis conducted to better assess the overall relationships of the alleles at the relevant loci (Glu-A1, Glu-A3, and Glu-B3) with the quality traits. The first two axes of the PCAs accounted for $83-98 \%$ of the total variance. In all cases, gluten quality resulted clearly associated with the main PC1 axis, with SDSS and TM in the positive direction. Protein content and BDR were mostly associated with the negative PC1 values but their position along the PC2 axis resulted in more variation between the three PCA analyses. In agreement with the main results described above, this approach confirmed the outstanding effect on gluten properties of Glu-A1o allele (Figure $4 \mathrm{a}$ ), the remarkable beneficial influence of the subunit combination $5+8^{*}$ and weaker properties derived of allele $d$ at Glu-A3 (Figure 4b), and the positive relation with gluten quality of the allele $a$ and the combination $13^{*}+15+19$ among the allelic variants analyzed at Glu-B3 (Figure 4c). 
a)

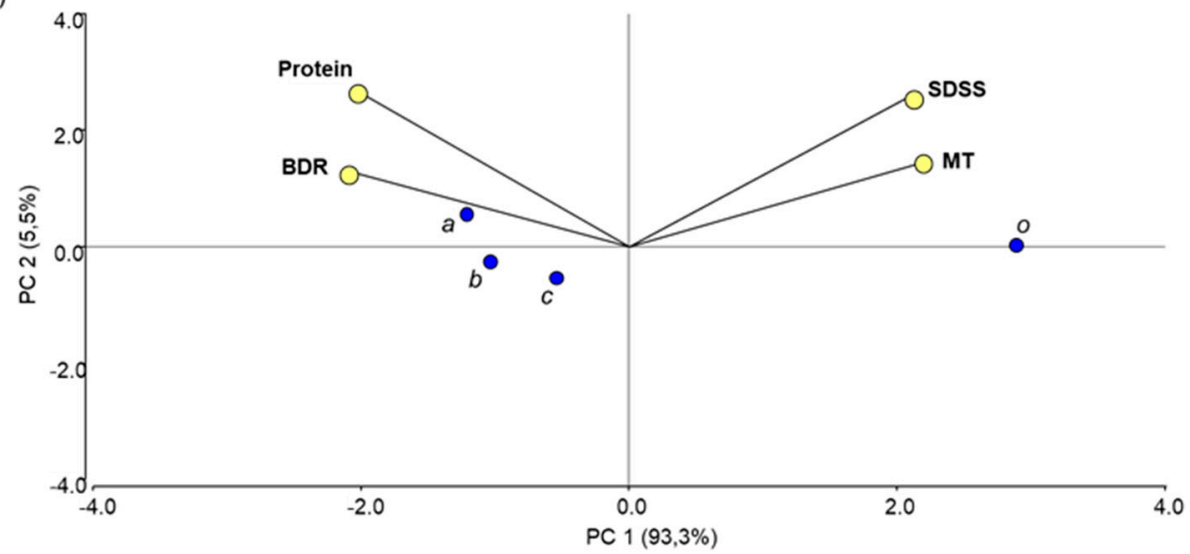

b)
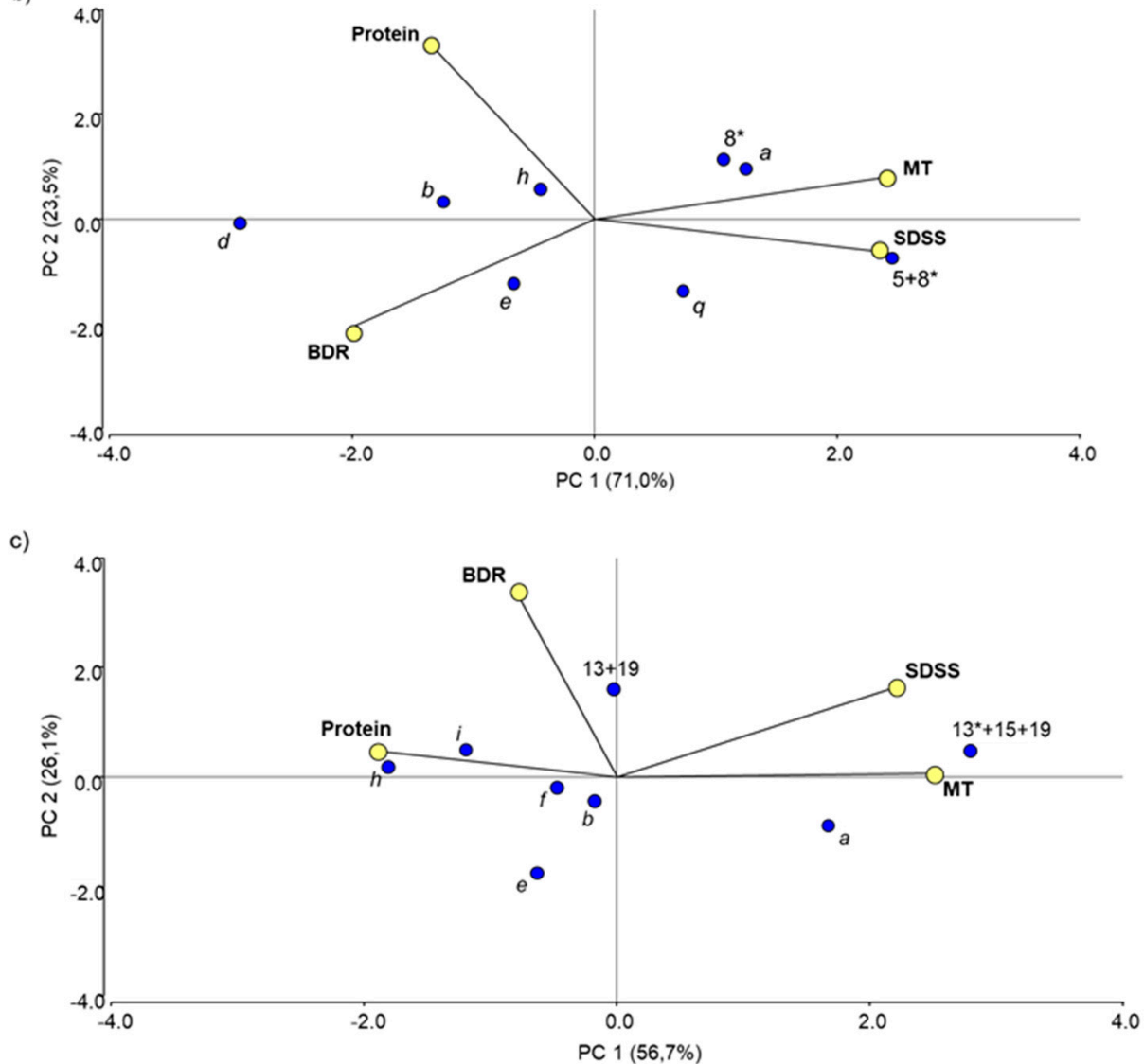

Figure 4. First and second principal components for the alleles present in at least three landraces and the quality traits. (a) Glu-A1. (b) Glu-A3. (c) Glu-B3.

\subsubsection{Non-Allelic Interactions between Prolamin Loci}

The analysis of allelic variation at a single locus facilitates the identification of alleles having a relevant effect on a trait, particularly when the loci under study are highly polymorphic. However, gluten performance is the outcome of complex interactions between the glutenin and gliadin protein subunits encoded by the whole set of prolamin loci. Further multivariate PCA analyses were then conducted to assess the influence of specific allelic combinations on gluten quality. The four landraces bearing the $G l u-A 1 o$ allele were excluded from these analyses to avoid that the outstanding influence of this allele could mask or bias the effects of the alleles that these accessions presented at the other prolamin loci. Such exclusion reduced the significance of the effect of allelic variation at Glu-A1 on SDSS $(F=3.82 ; p=0.024)$ and MT $(F=4.22 ; p=0.019)$ but not on BDR $(F=13.17 ; p>0.001)$, while 
the effects of the other prolamin loci remained virtually the same (compare ANOVA results in Table 2 and Supplementary Table S4). Then all the findings described below are based on a set of 112 durum wheat landraces.

A first multivariate PCA analysis was conducted to determine the relationships with the quality traits of allele combinations at the LMWGS-encoding loci Glu-A3 and Glu-B3 (Figure 5a). Gluten quality resulted again clearly associated with the main PC1 axis, with SDSS and MT in the positive direction, and BDR in the negative direction. The high allelic variability found for these two loci in the germplasm collection explains that only half of the $20 \mathrm{Glu}-A 3: G l u B-3$ allele combinations were present in at least three landraces. Among these, the combinations involving Glu-B3a ( $a: a$ and $h: a$, with the Glu-A3 and Glu-B3 alleles being indicated in first and second place, respectively) were grouped together in the biplot space, despite Glu-A3a, but not Glu-A3h, was associated with good quality (Figure $4 \mathrm{~b}$ ). It supports the acknowledged relevance of the Glu-B3a allele on the good gluten properties of durum wheat $[14,43,51]$ and suggests some epistatic interaction of this allele over Glu- $A 3$. However, in the case of the bad gluten quality-related Glu-B3h allele, a non-allelic additive interaction with those Glu-A3 alleles seems to exists since the position of $a: h$ and $h: h$ in Figure 5 a fits the expected according to the relative positions of the $a$ and $h \mathrm{Glu}-A 3$ alleles in Figure $4 \mathrm{~b}$. Genotype combinations involving the allele Glu-A3q (subunits 5+20) can be highlighted among the represented by less than three landraces: $q: b, q: i$ and $q: 13+19$. It was remarkable, not only their different position along the PCA 1 axis, but especially that $q: i$ was the best performing since the overall influence of the Glu-B3i allele on the quality tests was similar or even worse than the findings for the Glu-B3b allele and the subunits $13+19$ (Table 2; Figure 4c). Furthermore, the finding that the landraces with $b: i$ and $h: i$ were placed in the opposite, negative, direction in Figure 5a suggests that the combination of the Glu-A3q and Glu-B3i might be particularly beneficial for improved gluten quality. Nevertheless, such a conclusion needs to be confirmed by further analysis of a larger sample of varieties bearing this Glu-A3:Glu-B3 allelic pattern.

As noted above, less influence of the HMW loci Glu-A1 and Glu-B1 on durum wheat quality has commonly been reported. However, our ANOVA analyses detected some significant effects of Glu-A1 on SDSS, MT and, particularly, BDR values (Table 2; see Supplementary Tables S3 and S4), and the existence of interactions between Glu-1 and Glu-3 loci on bread wheat gluten properties is already documented (reviewed in [55]). A latter PCA analysis was then conducted to assess whether allelic variation at this locus could actually modify the predicted durum wheat gluten behavior of specific genotype combinations of Glu-A3 and Glu-B3. This approach was focused on the commonest Glu- $A 1$ alleles $(a, b$ and $c)$ since the landraces bearing the Glu-A1o allele had been formerly excluded. The biplot of the first two axes is represented in Figure $5 \mathrm{~b}$ where, for clarity purposes, the genotype combinations that are expressly mentioned in the text below are indicated in red. The noting of alleles combinations in that Figure, and their references henceforth, follow the format "Glu-A1/Glu-A3:Glu-B3". The genotypic classes involving the Glu-A3 alleles $a$ and $h$ and the Glu-B3 alleles $a$ and $h$ (namely, $a: a, a: h, h: a$ and $h: h)$ were particularly suitable to assess the influence of Glu-A1 interaction because combinations of each of them with two or three distinct $G l u-A 1$ alleles could be analyzed. The relative positions of the allelic combinations $a / a: a, b / a: a$, and $c / a: a$ (in 2, 10 and 16 landraces, respectively) support a differential effect on gluten performance of the Glu-A1 alleles $a$ (subunit 1) and $c$ (null allele), which seem to exercise a deleterious and beneficial influence, respectively (Figure $5 b$ ). A differential effect of Glu-A1 alleles is also suggested by comparison between $a / a: h, b / a: h$ and $c / a: h$ (in 1,4 and 4 landraces). In this case, however, it is the Glu-A1b allele which shows a negative effect on quality. Less differences are found between the positions in the biplot space of the landraces with the allelic combinations $a / h: h$, $b / h: h$ and $c / h: h$ (in 2, 2, and 1 landraces), all in the negative direction of the PC1 axe, but it is the allele $c$ of Glu-A1 which seems to exercise the worst influence. Finally, a similar quality of $a / h: a$ and $c / h: a$ (in 3 and 9 landraces) could be deduced from their close position in the PCA biplot space. Some of these results need to be confirmed on a larger sample but support that a given $G l u-A 1$ allele can show different effects on gluten properties depending on the genetic background at LMW loci Glu-A3 and Glu-B3. It may explain the difficulty to demonstrate clear consistent effects of the HMW Glu-A1 locus 
on durum wheat quality [49]. The underlying reasons for such unpredictable influence are surely related to the complexity of the molecular interactions in the glutenin polymers that determine dough properties [56].

a)
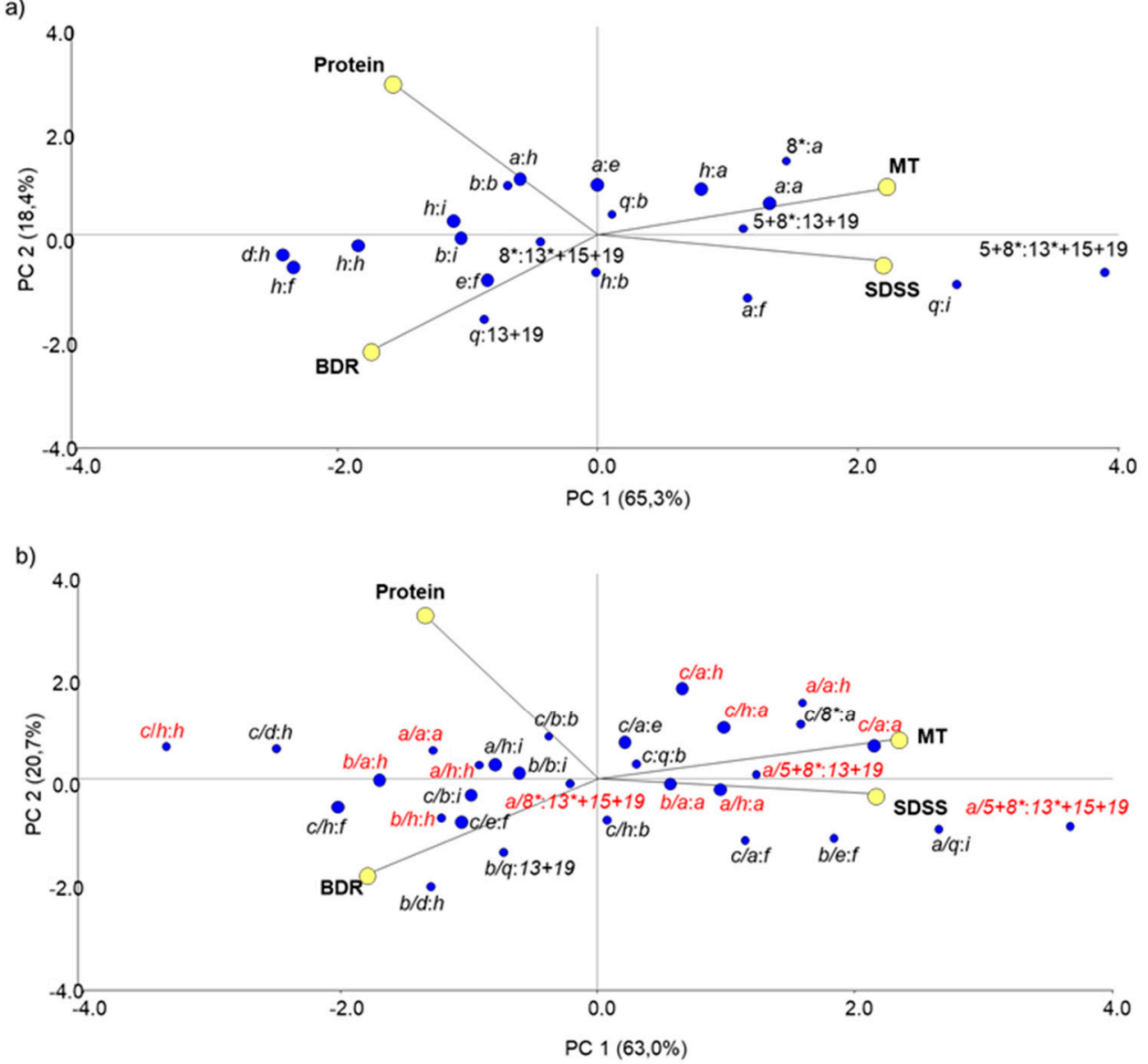

Figure 5. First and second principal components for non-allelic combinations and the quality traits. Combinations present in at least three landraces are indicated by larger dots. (a) Allele combinations between the LMW loci Glu-A3 and Glu-B3. (b) Allele combinations involving the HMW locus Glu-A1 and the Glu-A3 and Glu-B3 LMW loci. The combinations mentioned in the text are indicated in red.

No conclusion can be drawn about the conserved position in Figure $5 \mathrm{a}, \mathrm{b}$ of some of the Glu-A3:Glu-B3 subunits combinations highlighted above (i.e., $5+8^{*}: 13^{*}+15+19,5+8^{*}: 13+19$, or $\left.8^{*}: 13^{*}+15+19\right)$ since no variability at Glu-A1 was found within the sample of landraces that presented each of them. The identification of these prolamin profiles in more durum wheat accessions would allow, firstly, to confirm their apparently beneficial effects on gluten properties and, secondly, to determine the possible existence of modulating effects involving Glu-A1 alleles.

\section{Conclusions}

The study conducted has identified some durum wheat landraces that could be directly used in farming agrosystems interested in the cultivation of traditional varieties. Among them, those bearing the Glu-A1o allele can be highlighted. Future studies need to be made to confirm the beneficial influence of this allele, which could be included in breeding programs for enhancing wheat quality. We have also characterized new alleles and allele combinations at Glu-A3 and GluB3 associated with better gluten properties. Most of the novel variation described here was present in a reduced number of accessions. Ongoing research efforts on local wheat germplasm may enlarge the samples allowing to further prove their utility as genetic markers for durum wheat quality improvement. 
Supplementary Materials: The following are available online at http://www.mdpi.com/2073-4395/10/1/136/s1, Figure S1: MALDI-TOF mass spectrum for the Spanish landrace with the 20x subunit at locus Glu-B1 (BGE 021769), Table S1: CRF gene-bank code and local name of the 116 durum wheat Spanish landraces analyzed. Their allelic pattern for the prolamin loci studied and data for the quality variables examined is included. The BGE number of the landraces that could not be analyzed in 2015 is in red lettering, Table S2: Pearson's correlation tests to analyze the relation between protein content and SDS sedimentation volume values obtained in 2012 and 2015 , and between the quality traits examined, Table S3: Mean squares (MS) and F-values as determined by ANOVA showing the effect of the prolamin loci on grain protein content, SDS sedimentation volume and mixograph parameters. The effect of the year and $\mathrm{G} \times \mathrm{E}$ (year) interactions is also considered for protein content and SDSS-test values, Table S4: Mean squares (MS) and F-values as determined by ANOVA showing the effect of the prolamin loci on protein content, SDS sedimentation volume and mixograph parameters if the four landraces bearing the $G l u-A 10$ allele are excluded from the analyses. The effect of the year is also considered for protein content and SDSS-test values.

Author Contributions: Conceptualization, F.J.V., J.M.C. and M.R.-Q.; data curation, E.A.C. and M.R.-Q.; formal analysis, E.A.C., P.G., E.B. and M.R.-Q.; funding acquisition, P.G. and J.M.C.; investigation, E.A.C. and M.R.-Q.; methodology, F.J.V., P.G. and M.R.-Q.; project administration, F.J.V. and M.R.-Q.; resources, F.J.V.; supervision, J.M.C. and M.R.-Q.; validation, E.B. and M.R.-Q.; visualization, E.A.C., E.B. and M.R.-Q.; writing-original draft, E.A.C., E.B. and M.R.-Q.; writing-review and editing, E.A.C., P.G., J.M.C., E.B. and M.R.-Q. All authors have read and agreed to the published version of the manuscript.

Funding: This research was funded by projects AGL 2012-38345 and AGL2016-77149 of the Spanish Ministry of Science, Innovation, and Universities, which also supported EA Chacón with a research grant (BES-2013-065575).

Acknowledgments: The authors are grateful to the CRF-INIA which kindly supplied seed samples of the Spanish durum wheat landraces used in the study and to M. Ruiz for helpful comments during the preparation of the original and revised versions of the manuscript.

Conflicts of Interest: The authors declare no conflict of interest.

\section{References}

1. Kabbaj, H.; Sall, A.T.; Al-Abdallat, A.; Geleta, M.; Amri, A.; Filali-Maltouf, A.; Belkadi, B.; Ortiz, R.; Bassi, F.M. Genetic diversity within a global panel of durum wheat (Triticum durum) landraces and modern germplasm reveals the history of alleles exchange. Front. Plant Sci. 2017, 8, 1277. [CrossRef] [PubMed]

2. MacKey, J. Wheat: Its concept, evolution, and taxonomy. In Durum Wheat Breeding: Current Approaches and Future Strategies; Royo, C., Nachit, M., Di Fonzo, N., Araus, J.L., Pfeiffer, W.H., Slafer, G.A., Eds.; Haworth Press: Binghamton, NY, USA, 2005; Volume 1, pp. 3-62.

3. Feldman, M. Origin of cultivated wheat. In The World Wheat Book: A History of Wheat Breeding; Bonjean, A.P., Angus, W.J., Eds.; Lavoisier Publishing: Paris, France, 2001; Volume 1, pp. 3-56.

4. Ortiz, R.; Trethowan, R.; Ferrara, G.O.; Iwanaga, M.; Dodds, J.H.; Crouch, J.H.; Crossa, J.; Braun, H.-J. High yield potential, shuttle breeding, genetic diversity, and a new international wheat improvement strategy. Euphytica 2007, 157, 365-384. [CrossRef]

5. Reif, J.C.; Zhang, P.; Dreisigacker, S.; Warburton, M.L.; van Ginkel, M.; Hoisington, D.; Bohn, M.; Melchinger, A.E. Wheat genetic diversity trends during domestication and breeding. Theor. Appl. Genet. 2005, 110, 859-864. [CrossRef] [PubMed]

6. Mefleh, M.; Conte, P.; Fadda, C.; Giunta, F.; Piga, A.; Hassoun, G.; Motzo, R. From ancient to old and modern durum wheat varieties: Interaction among cultivar traits, management, and technological quality. J. Sci. Food Agric. 2019, 99, 2059-2067. [CrossRef]

7. Food and Agriculture Organization. FAO Statistical Yearbook, World Food and Agriculture; Food and Agriculture Organization: Rome, Italy, 2013; p. 307.

8. Berni, R.; Cantini, C.; Romi, M.; Hausman, J.-F.; Guerriero, G.; Cai, G. Agrobiotechnology goes wild: Ancient local varieties as sources of bioactives. Int. J. Mol. Sci. 2018, 19, 2248. [CrossRef]

9. Osborne, T.B. The Vegetable Proteins, 2nd ed.; Longmans, Green and Co.: London, UK, 1924; pp. 1-154.

10. Damidaux, R.; Autran, J.; Grignac, P.; Feillet, P. Evidence of relationships useful for breeding between the electrophoretic patterns of gliadins and the viscoelastic properties of the gluten in Triticum durum. Comptes Rendus Hebd. Seances Acad. Sci. Ser. D Sci. Nat. 1978, 287, 701-704. 
11. Payne, P.I.; Jackson, E.A.; Holt, L.M. The association between $\gamma$-gliadin 45 and gluten strength in durum wheat varieties: A direct causal effect or the result of genetic linkage? J. Cereal Sci. 1984, 2, 73-81. [CrossRef]

12. Ruiz, M.; Carrillo, J.M. Relationships between different prolamin proteins and some quality properties in durum wheat. Plant Breed. 1995, 114, 40-44. [CrossRef]

13. Vazquez, J.F.; Ruiz, M.; Nieto-Taladriz, M.T.; Albuquerque, M.M. Effects on Gluten Strength of Low Mr Glutenin Subunits Coded by Alleles at Glu-A3 and Glu-B3 Loci in Durum Wheat. J. Cereal Sci. 1996, 24, 125-130. [CrossRef]

14. Carrillo, J.M.; Martinez, M.C.; Brites, C.; Nieto-Taladriz, M.T.; Vázquez, J.F. Relationship between endosperm proteins and quality in durum wheat (Triticum turgidum L. var. durum). Options Méditerranéennes 2000, 40, 463-467.

15. Aguiriano, E.; Ruiz, M.; Fité, R.; Carrillo, J.M. Genetic variation for glutenin and gliadins associated with quality in durum wheat (Triticum turgidum L. ssp. turgidum) landraces from Spain. Span. J. Agric. Res. 2008, 6, 599-609. [CrossRef]

16. Moragues, M.; del Moral, L.F.G.; Moralejo, M.; Royo, C. Yield formation strategies of durum wheat landraces with distinct pattern of dispersal within the Mediterranean basin I: Yield components. Field Crops Res. 2006, 95, 194-205. [CrossRef]

17. Nazco, R.; Peña, R.J.; Ammar, K.; Villegas, D.; Crossa, J.; Moragues, M.; Royo, C. Variability in glutenin subunit composition of Mediterranean durum wheat germplasm and its relationship with gluten strength. $J$. Agric. Sci. 2014, 152, 379-393. [CrossRef] [PubMed]

18. Ruiz, M.; Bernal, G.; Giraldo, P. An update of low molecular weight glutenin subunits in durum wheat relevant to breeding for quality. J. Cereal Sci. 2018, 83, 236-244. [CrossRef]

19. Singh, N.K.; Shepherd, K.W.; Cornish, G.B. A simplified SDS-PAGE procedure for separating LMW subunits of glutenin. J. Cereal Sci. 1991, 14, 203-208. [CrossRef]

20. Payne, P.I.; Law, C.N.; Mudd, E.E. Control by homoeologous group 1 chromosomes of the high-molecular-weight subunits of glutenin, a major protein of wheat endosperm. Theor. Appl. Genet. 1980, 58, 113-120. [CrossRef]

21. Lafiandra, D.; Kasarda, D.D. One-and two-dimensional (two-pH) polyacrylamide gel electrophoresis in a single gel: Separation of wheat proteins. Cereal Chem. 1985, 62, 314-319.

22. Payne, P.I.; Lawrence, G.J. Catalogue of alleles for the complex gene loci, Glu-A1, Glu-B1, and Glu-D1 which code for high-molecular-weight subunits of glutenin in hexaploid wheat. Cereal Res. Commun. 1983, 11, 29-35.

23. McIntosh, R.; Dubcovsky, J.; Rogers, J.W.; Morris, C.; Appels, R.; Xia, X. Catalogue of gene symbols for wheat: 2013-14 Supplement. Annu. Wheat Newsl. 2014, 58, 259-279.

24. Nieto-Taladriz, M.T.; Ruiz, M.; Martinez, M.C.; Vazquez, J.F.; Carrillo, J.M. Variation and classification of B low-molecular-weight glutenin subunit alleles in durum wheat. Theor. Appl. Genet. 1997, 95, 1155-1160. [CrossRef]

25. Kudryavtsev, A.M.; Illichevskii, N.N.; Boggini, G.; Benedettelli, S. Gliadin polymorphism and genetic diversity of modern Italian durum wheat. J. Genet. Breed. 1996, 50, 239-248.

26. Sechi, S.; Chait, B.T. Modification of cysteine residues by alkylation. A tool in peptide mapping and protein identification. Anal. Chem. 1998, 70, 5150-5158. [CrossRef] [PubMed]

27. Dick, J.W.; Quick, J.S. A Modified Screening-Test for rapid estimation of gluten strength in early-generation durum-wheat breeding lines. Cereal Chem. 1983, 60, 315-318.

28. Carrillo, J.M.; Vazquez, J.F.; Orellana, J. Relationship between gluten strength and glutenin proteins in durum wheat cultivars. Plant Breed. 1990, 104, 325-333. [CrossRef]

29. Finney, K.F.; Shogren, M.D. A ten-gram mixograph for determining and predicting functional properties of wheat flours. Bak. Dig. 1972, 46, 32-47.

30. InfoStat v2016; Grupo Infostat, FCA, Universidad Nacional de Córdoba: Córdoba, Argentina, 2016.

31. Zeven, A.C. Landraces: A review of definitions and classifications. Euphytica 1998, 104, 127-139. [CrossRef]

32. Ruiz, M.; Vazquez, J.; Carrillo, J. Estudio de la variabilidad de gluteninas y gliadinas en variedades locales y cultivares primitivos españoles de trigo duro. Invest. Agric. Prod. Prot. Veg. 1998, 13, 291-305.

33. Cherdouh, A.; Khelifi, D.; Carrillo, J.; Nieto-Taladriz, M. The high and low molecular weight glutenin subunit polymorphism of Algerian durum wheat landraces and old cultivars. Plant Breed. 2005, 124, 338-342. [CrossRef] 
34. Brites, C.; Romano, M.; Sousa, R.; Vazquez, J.; Carrillo, J. Caracterizaçao das proteinas de reserva da colecçao de trigos rijos Portugueses: Diversidade e qualidade tecnologica. Melhoramento 1996, 34, 55-66.

35. Raciti, C.; Doust, M.; Lombardo, G.; Boggini, G.; Pecetti, L. Characterization of durum wheat mediterranean germplasm for high and low molecular weight glutenin subunits in relation with quality. Eur. J. Agron. 2003, 19, 373-382. [CrossRef]

36. Babay, E.; Hanana, M.; Mzid, R.; Slim-Amara, H.; Carrillo, J.M.; Rodríguez-Quijano, M. Influence of allelic prolamin variation and localities on durum wheat quality. J. Cereal Sci. 2015, 63, 27-34. [CrossRef]

37. Vallega, V.; Mello-Sampayo, T. Variation of high-molecular-weight glutenin subunits amongst cultivars of Triticum turgidum L. from Portugal. Euphytica 1987, 36, 755-762. [CrossRef]

38. Branlard, G.; Autran, J.; Monneveux, P. High molecular weight glutenin subunit in durum wheat (T. durum). Theor. Appl. Genet. 1989, 78, 353-358. [CrossRef] [PubMed]

39. Igrejas, G.; Guedes-Pinto, H.; Carnide, V.; Branlard, G. The high and low molecular weight glutenin subunits and $\omega$-gliadin composition of bread and durum wheats commonly grown in Portugal. Plant Breed. 1999, 118, 297-302. [CrossRef]

40. Ribeiro, M.; Rodríguez-Quijano, M.; Giraldo, P.; Pinto, L.; Vázquez, J.F.; Carrillo, J.M.; Igrejas, G. Effect of allelic variation at glutenin and puroindoline loci on bread-making quality: Favorable combinations occur in less toxic varieties of wheat for celiac patients. Eur. Food Res. Technol. 2017, 243, 743-752. [CrossRef]

41. Rodriguez-Quijano, M.; Vazquez, J.; Carrillo, J.; Moita Brites, C. Allelic variation of HMW glutenin subunits in Portuguese landraces of Triticum aestivum ssp. vulgare. J. Genet. Breed. 1998, 52, 95-98.

42. Brites, C.; Carrillo, J. Inheritance of gliadin and glutenin proteins in four durum wheat crosses. Cereal Res. Commun. 2000, 28, 239-246.

43. Martinez, M.C.; Ruiz, M.; Carrillo, J.M. New B low Mr glutenin subunit alleles at the Glu-A3, Glu-B2 and Glu-B3 loci and their relationship with gluten strength in durum wheat. J. Cereal Sci. 2004, 40, 101-107. [CrossRef]

44. Rodríguez-Quijano, M.; Lucas, R.; Ruiz, M.; Giraldo, P.; Espí, A.; Carrillo, J.M. Allelic variation and geographical patterns of prolamins in the USDA-ARS Khorasan wheat germplasm collection. Crop Sci. 2010, 50, 2383-2391. [CrossRef]

45. Ribeiro, M.; Carvalho, C.; Carnide, V.; Guedes-Pinto, H.; Igrejas, G. Towards allelic diversity in the storage proteins of old and currently growing tetraploid and hexaploid wheats in Portugal. Genet. Resour. Crop Evol. 2011, 58, 1051-1073. [CrossRef]

46. Aguiriano, E.; Ruiz, M.; Fité, R.; Carrillo, J.M. Analysis of genetic variability in a sample of the durum wheat (Triticum durum Desf.) Spanish collection based on gliadin markers. Genet. Resour. Crop Evol. 2006, 53, 1543-1552. [CrossRef]

47. Peña, R.; Trethowan, R.; Pfeiffer, W.; Ginkel, M.V. Quality (end-use) improvement in wheat: Compositional, genetic, and environmental factors. J. Crop Prod. 2002, 5, 1-37. [CrossRef]

48. Brites, C.; Carrillo, J. Influence of high molecular weight (HMW) and low molecular weight (LMW) glutenin subunits controlled by Glu-1 and Glu-3 loci on durum wheat quality. Cereal Chem. 2001, 78, 59-63. [CrossRef]

49. Martinez, M.C.; Ruiz, M.; Carrillo, J.M. Effects of different prolamin alleles on durum wheat quality properties. J. Cereal Sci. 2005, 41, 123-131. [CrossRef]

50. Magallanes-López, A.M.; Ammar, K.; Morales-Dorantes, A.; González-Santoyo, H.; Crossa, J.; Guzmán, C. Grain quality traits of commercial durum wheat varieties and their relationships with drought stress and glutenins composition. J. Cereal Sci. 2017, 75, 1-9. [CrossRef]

51. Nieto-Taladriz, M.T.; Rodriguez-Quijano, M.; Carrillo, J.M. Glutenin proteins as markers for durum wheat quality selection. In Proceedings of the Actes du 1er Symposium International sur la Filière Blé, Office Algérien Interprofessionnel des céréales, Algiers, Algeria, 7-9 February 2010; pp. 267-270.

52. Cros, D.; Wrigley, C.; Hare, R. Prediction of durum-wheat quality from gliadin-protein composition. Aust. J. Agric. Res. 1982, 33, 429-442. [CrossRef]

53. Pogna, N.; Autran, J.-C.; Mellini, F.; Lafiandra, D.; Feillet, P. Chromosome 1B-encoded gliadins and glutenin subunits in durum wheat: Genetics and relationship to gluten strength. J. Cereal Sci. 1990, 11, 15-34. [CrossRef]

54. Aguiriano, E.; Ruiz, M.; Fité, R.; Carrillo, J. Effects of N fertilisation, year and prolamin alleles on gluten quality in durum wheat (Triticum turgidum L. ssp. turgidum) landraces from Spain. Span. J. Agric. Res. 2009, 7, 342-348. [CrossRef] 
55. Shewry, P.R.; Halford, N.G.; Lafiandra, D. Genetics of wheat gluten proteins. In Advances in Genetics; Academic Press: San Diego, CA, USA, 2003; Volume 49, pp. 111-184.

56. Gianibelli, M.C.; Larroque, O.R.; MacRitchie, F.; Wrigley, C.W. Biochemical, genetic, and molecular characterization of wheat glutenin and its component subunits. Cereal Chem. 2001, 78, 635-646. [CrossRef]

(C) 2020 by the authors. Licensee MDPI, Basel, Switzerland. This article is an open access article distributed under the terms and conditions of the Creative Commons Attribution (CC BY) license (http://creativecommons.org/licenses/by/4.0/). 